\title{
The concept of sphingolipid rheostat in skin: a driving force for new active ingredients in cosmetic applications
}

\author{
Iuliana Popa* \\ Faculty of Pharmacy, University of Paris-Sud, Chatenay-Malabry, France
}

Received 19 April 2018 - Accepted 29 July 2018

\begin{abstract}
Skin is a representative model of the complex metabolism that lipids may trigger. It is known that the biosynthesis of these lipids in mammalian cells generally ensures the cell membranes stability and participates to the signaling function. In the inner layers of the skin, the "de-novo" synthesis is the driving force ensuring proliferation, development and intercellular signaling. To promote stratum corneum formation, lipid catabolism leads to the renewal of ceramides, fatty acids and cholesterol that are responsible for the cohesion of the stratum corneum, its permeability, hydration, moisturization and signalling with the outer skin layers, appendages and inner layers secretion (cytokines, neuropeptides). Some actives applied in local treatments (i.e., peptides, n-3 polyunsaturated fatty acids (PUFA), ceramides, urea or an aqueous extract of Gromwell) and in oral treatment (i.e., sphingomyelin, n-3 polyunsaturated fatty acids (PUFA)) promote sphingosine 1-phosphate (S1P) production by the sphingolipid rheostat via triggering the salvage process along with autophagy and detoxification in aged skin. This review gives some basis for using the concept of sphingolipid metabolism rheostat in skin as the driving force for the development of new cosmetic actives ingredients or for repositioning the benefits of other actives for the skin.
\end{abstract}

Keywords: de-novo lipid metabolism / lipid catabolism / skin / sphingolipid rheostat

\begin{abstract}
Résumé - Le concept de rhéostat sphingolipidique dans la peau: un moteur pour de nouveaux ingrédients actifs dans les applications cosmétiques. La peau est le modèle représentatif du métabolisme lipidique complexe. Il est connu que la biosynthèse lipidique au niveau cellulaire assure la stabilité membranaire et participe au fonctionnement de la signalisation cellulaire. Dans les couches profondes de la peau, le métabolisme «de-novo» est prédominant, car il participe à la prolifération cellulaire, à son développement et à sa signalisation. Pour obtenir la couche cornée, le catabolisme lipidique va conduire au renouvellement des céramides, des acides gras et du cholestérol, responsables de la cohésion de la couche cornée, de sa perméabilité, de son hydratation et son contenu en eau, et de la signalisation dans les couches superficielles cutanées, les appendices cutanés et les couches profondes (cytokines, neuropeptides). Certain actifs en application locale (i.e., peptides, n-3 acides gras polyinsaturés (PUFA), céramides, urée ou l'extrait aqueux Gromwell), ou par voie orale (i.e., sphingomyeline, n-3 acides gras polyinsaturés (PUFA), montrent une augmentation de la production de sphingosine 1-phosphate (S1P) par l'activation du rhéostat sphingolipidique par la voie du sauvetage, de l'autophagie et de la détoxification dans la peau âgée. Cette revue peut constituer une base dans l'utilisation du concept de rhéostat sphingolipidique comme une force motrice, dans le développement de nouveaux actifs cosmétiques, et pour le repositionnement des actifs existant qui apportent des effets bénéfiques à la peau.
\end{abstract}

Mots clés : métabolisme lipidique de-novo / catabolisme lipidique / peau / rhéostat sphingolipidique

\section{Introduction}

The term "sphingolipids" was first used by Thudichum in 1884 to describe compounds found in the brain such as phosphosphingolipids, neutral and acidic glycosphingolipids,

*Correspondence: iuliana.popa@u-psud.fr and sphingomyelin (Thudichum, 1884). Later, a specific accumulation of sphingolipids was reported in several genetic diseases such as Niemann-Pick's disease (sphingomyelin), Gaucher's disease (cerebrosides), characterized by a defective catabolism.

From a functional perspective, they have a biological significance as they are an essential constituent of membranes 


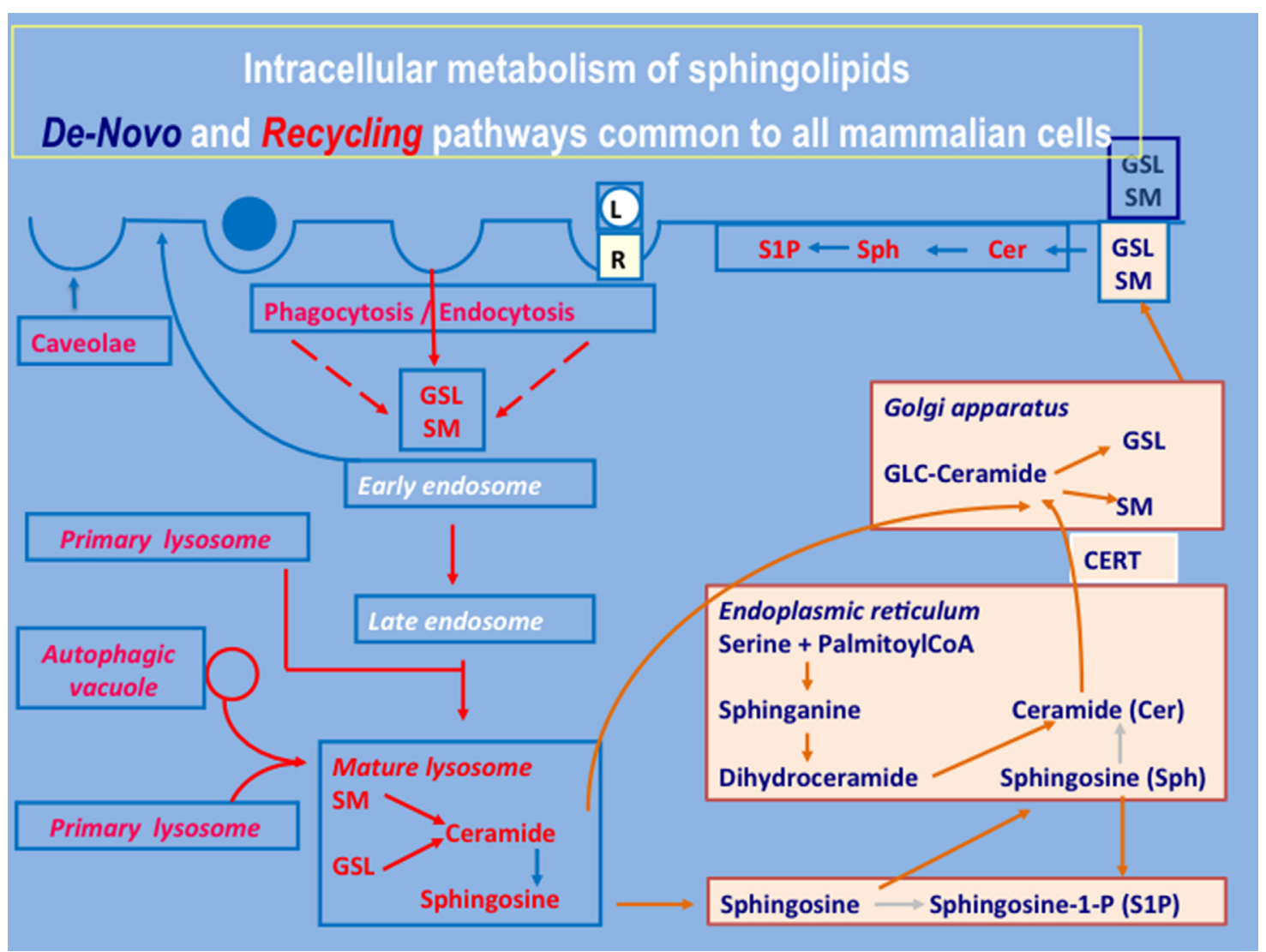

Fig. 1. De-novo and the recycling pathways of the sphingolipid metabolism in cells. Legend: De-Novo biosynthesis pathway of sphingolipid (on light panel and blue writing colors) and the Recycling pathway of sphingolipid in mammalian cells (on blue panel and red writing colours). SM: Sphingomyelin; GSL: Glycosphingolipids; L: Ligand, R: Receptor; GLC-Ceramide: Glucosyl-Ceramide; S1P: Sphingosine 1-Phosphate.

and lipoproteins present in animals, plants, fungi, procaryotic organisms and viruses. Some sphingolipids are specifically present in "rafts" and "caveolae" regions of the plasma membrane that are enriched in growth factors receptors or proteins transporters such as the glycosylphosphatidylinositollipid anchor (Hakomori et al., 1998; Brown and London, 2000; Merrill and Sandhoff, 2002; Tidhar and Futerman, 2013).

\section{Pathways of lipid biosynthesis in mammalian cells}

As shown in Figure 1, the de-novo biosynthesis of the long-chain backbone sphingoid base results from the condensation of palmitoyl-CoA and L-serine. The next step is the reduction of the formed 3-keto-sphinganine into sphinganine which is converted into a dihydroceramide (in the endoplasmic reticulum) by a ceramide synthase (Tidhar and Futerman, 2013). Subsequently, dihydroceramide is reduced to ceramide.

These ceramides are transported by ceramide transporter proteins (CERT) (Hanada et al.,, 2003) in the Golgi apparatus where ceramide can have multiple fates. It can be converted into sphingomyelin (SM) by the sphingomyelin synthase (SMS) in the lumen of the Golgi apparatus, into glucosylceramide (GLC) (and to more complex glycosphingolipids, GSL) on the cytosolic surface by the glucosylceramide synthase
(GCS), and it can be phosphorylated by a ceramide kinase (CK) to form ceramide-1-phosphate (Futerman and Pagano, 1991).

The complex sphingolipids and phospholipids are transported to the plasma membrane where, in addition to their structural role, they are involved in cell membrane signaling as growth factors, as co-receptors, in cell motility and invasion, and in membrane autophagy recycling.

Endocytosis of complex sphingolipids by the catabolic pathway involves endocytic pathways, hydrolysis and degradation into ceramides and sphingosine that are known as growth inhibitory and pro-apoptotic factors (Merrill et al., 1985). In addition to the de-novo synthesis and the recycling pathways (Fig. 1), the salvage and degradation pathways modulate cellular levels of sphingolipids. By these pathways, ceramide regeneration is obtained from complex sphingolipid reservoirs, such as glycosphingolipids (GSL) and sphingomyelins (SM), through the action of specific hydrolases and phosphodiesterases (Young et al., 2012).

\section{The sphingolipid rheostat defines the cell state}

The sphingolipid rheostat (Kolesnick et al., 2000; Spiegel and Milstein, 2000) defines the regulation of sphingolipid cellular metabolism in which ceramide displays a pro- 


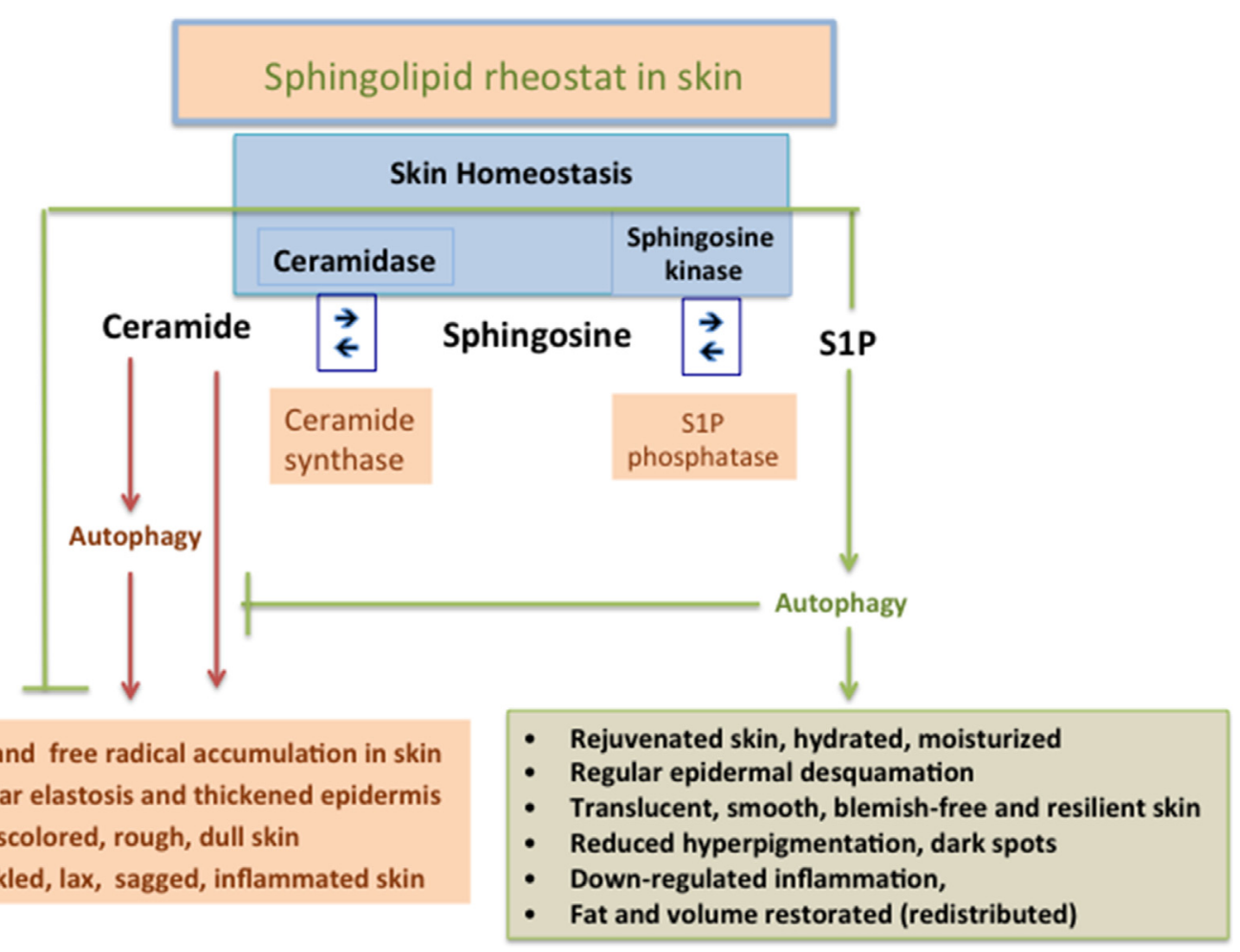

Fig. 2. The concept of sphingolipid rheostat in skin.

apoptotic role whereas sphingosine 1-phosphate is associated with a mitogenic and anti-apoptotic role. Modulation and regulation of this rheostat thus determines the cell survival versus cell death pathways.

As we will observe in this review, the sphingoid-based rheostat activates or inhibits a remarkable number of cellular events such as growth, division, apoptosis, autophagy, cytoskeleton and junctions formation, or extracellular metabolic events such as intercellular junction formation, extracellular matrix formation, paracrine and autocrine signalling.

Based on the concept of sphingolipid rheostat, several roles have been reported for ceramides such as induction of apoptosis (Fig. 2). Recently, it was found that the expression of CerS1 generating $\mathrm{C} 18$-ceramide resulted in the ceramide localization to MAM (Mitochondria-Associated Membranes) (Ardail et al., 2001) that could be involved in mitophagy induction (Babiychuk et al., 2011; Kogot-Levin and Saada, 2014).

It was reported that a specific lipogenic capacity is variable for the cells from different tissues and organs in the body. For example, liver is the major site of biosynthesis of total lipids and fatty acids (up to $37 \%$ of the lipid biosynthesis in the whole body), followed by the hypodermis with $24 \%$ and the epidermis with $8 \%$, small intestine with $1-2 \%$ while the musculature and skeleton contribute for $25 \%$ to the lipid synthesis of the body (Gandemer et al., 1983).

\section{Sphingolipid metabolism and skin homeostasis}

Skin has a very complex structure and contains four main layers: the innermost subcutaneous fat layer (hypodermis), the overlying dermis, the viable epidermis and the outermost layer of the tissue is a non-viable epidermal layer, the stratum corneum.

The epidermis is itself a complex multiply layered membrane, yet varies in thickness from around $0.06 \mathrm{~mm}$ on the eyelids to around $0.8 \mathrm{~mm}$ on the load-bearing palms and soles of the feet.

In skin, as in other mammalian cells, sphingolipids are ubiquitous components of cell membranes and are involved in several major biological activities, such as growth regulation (Spiegel and Merrill, 1996), differentiation and apoptosis (Hannun and Obeid, 1997). The modulation of these functions by sphingolipids seems to depend mainly on the constitutive sphingoid bases (Ohta et al., 1994). Sphingolipids regulate receptors for platelet-derived growth factor (PDGF) and epidermal growth factor (EGF). They are also involved in the co-evolution of transmembrane domains (TMD) and the formation of specialized glycosphingolipid-enriched microdomains (Ernst et al., 2014).

During proliferation, differentiation and aging of keratinocytes, sphingolipid metabolism is continuously changing (Ponec, 1991). Whereas the most undifferentiated layers of the epidermis (basal, spinosum and granulosum layers) contain mostly membrane lipids such as phospholipids, the differentiated keratinocytes contain ceramides, cholesterol and fatty acids predominantly. The lamellar bodies, appear in the granulosum layer, contain mostly glucosylceramides that are then hydrolyzed by a glucocerebrosidase into ceramides, the major components of the intercellular matrix of corneocytes layers (Hamanaka et al., 1993). The barrier function of the stratum corneum depends on the high proportion of proteinbound omega hydroxy ceramides along with free ceramides and other lipids (wax esters, cholesterol, fatty acids). 
Most scientific research underlines the link between the metabolism of several skin lipids and focuses mainly on the ceramides, or more specifically on the protein-bound ceramides, as indicators of homeostasis of the skin barrier, but as shown in a recent article, various lipids species (18 prostanoids, 12 hydroxy fatty acids, 9 endocannabinoids and $\mathrm{N}$-acyl ethanolamides, 21 non-hydroxylated ceramides and sphingoid bases) (Kendall et al., 2015) cooperate with proteins to give the specific conformational ordering and lateral packing required for the maintenance of a good homeostatic barrier (Mojumdar et al., 2014).

As confirmed also by other laboratories, the barrier function of the stratum corneum depends critically on its unique constituents; $75-80 \%$ as proteins, $5-15 \%$ as lipids with $5-10 \%$ unidentified on a dry weight basis (Wilkes et al., 1973). With regard to stratum corneum permeability, it was also reported that the amount of the $18 \mathrm{C}$ sphingosine-containing ceramides and the various acylceramides are key influencing factors (Janůšová et al., 2011).

\section{The sphingolipid rheostat in skin and the trends in anti-aging cosmetics}

As many researchers assumed, skin is a window for intrinsic (chronological) and extrinsic (photoaging) changes. The age-related changes in skin homeostasis are alterations due to the inherent apoptosis and free radical accumulation at a cellular level and translated at skin level to ageing processes and cumulative environmental damage (Fig. 2).

We observe, due to apoptosis and free radical accumulation in the dermis and epidermis, several chronological skin aging signs such as atrophy, laxity, fine wrinkles, loss of elasticity, dryness, contact dermatitis dermatosis, xerosis, fungal infections, seborrheic keratosis (Fig. 2). Photoaging (Krutmann and Gilchrest, 2006) can be associated with changes such as dyspigmentation, freckles, thick skin, deep wrinkles, melasma, citrine skin, senile purpura, pseudostellate scar, acrokeratoelastoidosis marginalis and lentigines ("age-spots"). Besides prolonged sun exposure, smoking is also a risk factor for aggravation resulting in sagging, dullness and inflamed skin (Fig. 2). Latterly, the totality of exposures to which an individual is subjected from conception to death is described by the "exposome" (Go and Jones, 2014; Krutmann et al., 2017) and aging is one of them. Otherwise, damage may result from repeated chemical assault of, for example, soaps or cosmetics.

In elder individuals, due to aging processes in their skin, the sphingolipid turnover is slower (Popa and Portoukalian, 2015). A heterogeneous distribution of lipids and the diminution of proteinbound lipids have been observed in aging stratum corneum leading to an impaired skin homeostasis and an impaired integrity (Denda et al., 2002). Dermal ageing was correlated with senescence in the dermis due to increased beta-galactosidase expression and accumulation of ceramides (Mouton and Venable, 2000).

As we can see from the following examples, some actives may induce the salvage way of the sphingolipid rheostat that is reflected by an anti-aging activity in epidermis and dermis, in hydration and water holding in stratum corneum and in barrier integrity, along with a rejuvenated skin presenting resilient, smooth, blemish-free and reduced hyperpigmentation appearance (Fig. 2).
In this respect, it was shown that epidermis homeostasis could be restored by local treatments with sphingosine 1phosphate (Japtok et al., 2014), peptides extract, (Popa et al., 2006, 2010), n-3 polyunsaturated fatty acids (PUFA) (Popa et al., 2011, 2018; Kendall et al., 2017), ceramide-based formulation (Popa et al., 2012), and aqueous extract of Gromwell (Lithospermum erythrorhizon) (Kim et al., 2012) that induced a biosynthesis of sphingolipids. (i.e., proteinbound ceramides).

Urea, one of the most widely used cosmetic actives, showed an enhancement of barrier function by inducing epidermal differentiation, increasing lipid content and increasing antimicrobial peptide expression (Grether-Beck et al., 2012)

Another specific activity of the PUFA in epidermis is the activation of the TLR2 (co-localized in the lipid rafts of the cellular membrane) receptor pathway that induces the polarization of macrophages into the inflammation-driving M1 phenotype and contributes to immune defense via the synthesis and release of pro-inflammatory cytokines (Hellwing et al., 2018), Alternatively, a B vitamin, niacinamide, has been shown to increase the epidermal production of skin barrier lipids, (ceramides), and proteins (keratin, involucrin, and fillagrin) (Bissett et al., 2005)

In other studies, the anti-ageing effect of an aqueous extract of Gromwell (Lithospermum erythrorhizon) was associated (Kim et al., 2012) with the increase in both lipids markers for phopholipids and glucosylceramides in aged fibroblasts.

Otherwise, following oral administration of an active (Cosgrove et al., 2007) such as essential fatty acids n-3 polyunsaturated fatty acids (PUFA), the skin and stratum corneum showed increased production of protein-bound ceramides in atopic subjects (Popa et al., 2011), and in healthy subjects, an increase in free ceramides was shown in the stratum corneum (Popa et al., 2018).

Supplementation with sphingomyelin (SM) containing milk resulted in an significant improvement in facial skin moisture and reduction of wrinkles perception around the eyes (Higurashi et al., 2015) after 12 weeks of treatment. Another study showed a reduction of UV-induced damage by maintaining covalently-bound $\omega$-hydroxy ceramides at the physiological levels and down-regulating mRNA levels of acute inflammation-associated genes, including thymic stromal lymphopoietin, interleukin-1 beta, and interleukin-6 (Oba et al., 2015). The bio-distribution of sphingomyelin to the skin represented $20 \%$ of the total sphingomyelin metabolized in liver and hydrolyzed to sphingosine and fatty acids. The sphingolipid uptake in skin was correlated also with an increased capacity of water-holding in the hairless mice (Haruta-Ono et al., 2012).

The improvement of the differentiation process in epidermis by vitamin or cannabinoid analogs was shown along with the externalization of cadherin at desmosome localization and the activation of sphingosine-1-phosphate lyase (S1P-lyase) (Celli et al., 2012). This means that the sphingolipid metabolism is representative of the organ integrity state.

As we can see from the afore mentioned work, sphingolipid metabolism modulates and balances cell and organ homeostasis and, based on their intrinsic activity, sphingolipids are proposed to be used alone or as complexes 
with other molecules as penetration enhancer or retarder molecules (Benson, 2005).

For example, they are used:

- as complexes with dextrose molecules $(\alpha-, \beta-, \gamma$-cyclodextrin) bound in a 1,4-configuration to form rings of various diameters;

- in vesicles as cosmetic products in which the active ingredients such as humectants like glycerol and urea, sunscreening and tanning agents, enzymes, are encapsulated;

- in liposomes where, with other colloidal particles, they form concentric biomolecular layers that are capable of encapsulating drugs;

- in transfersomes composed of phospholipids with 10-25\% surfactant (such as sodium cholate) and 3-10\% ethanol;

- in ethosomes containing a high alcohol quantity capable of enhancing penetration to deep tissues and the systemic circulation;

- in solid lipid nanoparticles (SLN) where they are used as carriers for enhanced skin delivery of sunscreens, vitamins $\mathrm{A}$ and E, triptolide and glucocorticoids.

The recovery of barrier homeostasis was also achieved through oral administration of $L$. reuteri by inducing control over perifollicular inflammation in stressed animals (Arck et al., 2010) or by restoring cutaneous $\mathrm{pH}$ and the protease activity in aged skin to the levels seen in young skin. The latter was induced by the fermentation of Lactobacilli and production of free fatty acids (FFAs) and conjugated linoleic acid (CLA) (Yadav et al., 2008).

Similarly, the recovery of the barrier homeostasis was shown in a 2-month pilot clinical study using a $0.2 \%$ phytosphingosine solution with antimicrobial activity against $P$. acnes that reduced by $89 \%$ acneiform papules and pustules compared to BPO (benzoyl peroxide) at 3.7\% (Pavicic et al., 2007). An anti-microbial efficacy of $90 \%$ microbial count reduction on the skin, after application of phytosphingosine at $1 \%$ compared to control (triclosan at $0.1 \%$ ), was also registered in the same work.

In another study, it was shown that the administration of vitamin $\mathrm{C}$ enhances the de-novo sphingolipid biosynthesis in epidermis and modulates the ratio sphinganine to sphingosine (Sa/So) in the stratum corneum (Kim et al., 2011).

This $\mathrm{Sa} / \mathrm{So}$ ratio influences barrier homeostasis because sphinganine induces antimicrobial activity and has a moisturising action in atopic skin lesions in humans, which relies on the enhancement of S1P lyase activity (Park et al., 2013).

In a recent study in mice infected with $S$. aureus and presenting respiratory cystic fibrosis (CF), inhalation of ceramides and sphingosine resulted in a significant prevention of pulmonary infections (including septic, MRSA exemplification, (Tavakoli et al., 2016).

Due to the microbiota and skin sphingolipids interconnecting and signaling, it was observed that the production of the cathelicidin peptides (CAMP), that are part of antimicrobial peptides (AMP) group, is triggered by the stimulation of sphingosine 1-phosphate content in keratinocytes which activates NFкBèC/EBP $\alpha$-pathway, (a dependent pathway that enhances CAMP production) (Park et al., 2013). In this study, resveratrol was used as an active to enhance cathelicidin antimicrobial peptide (CAMP) production and promote $S$. aureus growth inhibition while the sphingosine 1-phosphate content in keratinocyte was increased.

In addition to the above, it was shown that the dietary ingredient genistein stimulates cathelicidin antimicrobial peptide expression through the S1P-dependent rheostat by stimulating ceramide hydrolysis due to the activation of acidic and alkaline ceramidases, along with a corresponding decline in S1P lyase activity.

Similarly to resveratrol, genistein stimulates the pathway of $\mathrm{C} / \mathrm{EBP} \alpha \mathrm{mRNA}$ expression that regulates CAMP gene expression along with the sphingosine 1-phosphate content in keratinocytes. (Park et al., 2014).

In general, sphingoid bases (phytosphingosine, sphingosine) and fatty acids such as sapienic acid show a good skin antibacterial activity on the gram-positive and gram-negative bacteria $E$. coli, F. nucleatum, $S$. aureus, $S$. sanguinis and $S$. mitis (Benson, 2005). In this respect, the barrier homeostasis could be ensured by the management of a resilient and balanced skin microbiota that is associated with healthy ceramide production in stratum corneum. This leads to a moisturized skin and balanced sebum production (Kober and Bowe, 2015).

\section{Conclusions}

It is obvious that the sphingolipid rheostat plays a key role in cell development. As sphingolipids are involved in intracellular signal transduction and cell to cell connexions, they can be modulators of membrane proteins, act as bioactive lipid mediators in human skin (but also in the skin of other mammals such as mice and dogs), act as sensors in complex synapses with integrins and TPS, and co-localize with TLRs (ex: TLR2) within the lipid raft. S1P enhances antimicrobial defense through increased cathelicidin antimicrobial peptide (CAMP) production.

Ceramides, fatty acids, sphingosine, sphingosine 1phosphate are specific lipids modulators in intra- and intercellular triggering and promote skin homeostasis, with anti-aging and anti-inflammatory effects in skin.

Moreover, we notice that GSL (glycosphingolipids) promote modulation of actives, pro-actives, ion-pairs, supersaturated active solutions, eutectic systems, complexation, liposomes and vesicle penetration in skin.

Acknowledgements. Dr. Jacques Portoukalian, Pr. Thierry Levade and Dr. Adrian Watson for helpful discussions.

\section{References}

Arck P, Handjiski B, Hagen E, Pincus M, Bruenahl C, Bienenstock J, et al. 2010. Is there a "gut-brain-skin axis"? Exp Dermatol 19: 401-405.

Ardail D, Popa I, Alcantara K, Pons A, Zanetta JP, Louisot P, et al. 2001. Occurrence of ceramides and neutral glycolipids with unusual long-chain base composition in purified rat liver mitochondria. FEBS Lett 488: 160-164.

Babiychuk EB, Atanassoff AP, Monastyrskaya K, Brandenberger C, Studer D, Allemann C, et al. 2011. The targeting of plasmalemmal ceramide to mitochondria during apoptosis. PloSOne 6: e23706. 
Benson HAE. 2005. Transdermal drug delivery: Penetration enhancement techniques. Current Drug Delivery 2: 23-33.

Bissett DL, Oblong JE, Berge CA. 2005. Niacinamide: A B vitamin that improves aging facial skin appearance. Dermatol Surg 31: 865-865.

Brown DA, London E. 2000. Structure and function of sphingolipidand cholesterol-rich membrane rafts. J Biol Chem 27: 1722117224.

Celli A, Mackenzie DS, Zhai Y, Tu CL, Bikle DD, Holleran WM, et al. 2012. SERCA2-controlled $\mathrm{Ca}^{2+}$-dependent keratinocyte adhesion and differentiation is mediated via the sphingolipid pathway: a therapeutic target for Darier's disease. J Invest Dermatol 132: 1188-1195.

Cosgrove MC, Franco OH, Granger SP, Murray PG, Mayes AE. 2007. Dietary nutrient intakes and skin-aging appearance among middle-aged American women. Am J Clin Nutr 86: 1225-1231.

Denda M, Tsuchiya T, Elias PM, Feingold KR. 2002. Stress alters cutaneous permeability barrier homeostasis. Am J Physiol Regul Integr Comp Physiol 278: R367-R372.

Ernst AM, Brügger B. 2014. Sphingolipids as modulators of membrane proteins. Biochim Biophys Acta 1841: 665-670.

Futerman AH, Pagano RE. 1991. Determination of the intracellular sites and topology of glucosylceramide synthesis in rat liver. Biochem J 280: 295-302.

Gandemer G, Pascal G, Durand G. 1983. Lipogenic capacity and relative contribution of the different tissues and organs to lipid synthesis in male rat. Reprod Nutr Develop 23: 575-586.

Go YM, Jones DP. 2014. Redox biology: interface of the exposome with the proteome, epigenome and genome. Redox Biol 2: 358-360.

Grether-Beck S, Felsner I, Brenden H, Kohne Z, Majora M, Marini A, et al. 2012. Urea uptake enhances barrier function and antimicrobial defense in humans by regulating epidermal gene expression. J Invest Dermatol 132: 1561-1572. Doi: 10.1038/ jid.2012.42.

Hakomori S, Yamamura S, Handa AK. 1998. Signal transduction through glyco(sphingo)lipids. Introduction and recent studies on glyco(sphingo)lipid-enriched microdomains. Ann NY Acad Sci 845: $1-10$.

Hamanaka S, Takemoto T, Hamanaka Y, Asagami C, Suzuki M, Suzuki A, et al. 1993. Structure determination of glycosphingolipids of cultured human keratinocytes. Biochim Biophys Acta 1167: 1-8.

Hanada K, Kumagai K, Miura Y, Kawano M, Fukasawa M, Nishijima M. 2003. Molecular machinery for non-vesicular trafficking of ceramide. Nature 426: 803-809.

Hannun YA, Obeid LM. 1997. Mechanisms of ceramide-mediated apoptosis. Adv Exp Med Biol 407: 145-149.

Haruta-Ono Y, Setoguchi S, Ueno HM, Takata J. 2012. Orally administered sphingomyelin in bovine milk is incorporated into skin sphingolipids and is involved in the water-holding capacity in hairless mice. J Dermatol Sci 68: 56-62.

Hellwing C, Schoeniger A, Roessler C, Leimert A, Schumann J. 2018. Lipid raft localization of TLR 2 and its co-receptors is independent of membrane lipid composition. Peer J 6: e4212.

Higurashi S, Haruta-Ono Y, Urazono H, Kobayashi T, Kadooka Y. 2015. Improvement of skin condition by oral supplementation with sphingomyelin-containing milk phospholipids in a doubleblind, placebo-controlled, randomized trial. J Dairy Sci 98: 6706-6712.

Janůšová B, Zbytovská J, Lorenc P, Vavrysová H, Palát K, Hrabálek A, et al. 2011. Effect of ceramide acyl chain length on skin permeability and thermotropic phase behavior of model stratum corneum lipid membranes. Biochim Biophys Acta 1811: 129-137.

Japtok L, Bäumer W, Kleuser B. 2014. Sphingosine-1-phosphate as signaling molecule in the skin. Relevance in atopic dermatitis. Allergo J Int 23: 54-59.

Kendall AC, Pilkington SM, Massey KA, Sassano G, Rhodes LE, Nicoaou A. 2015. Distribution of bioactive lipid mediators in human skin. J Invest Dermatol 135: 1510-1520.

Kendall AC, Kiezel-Tsugunova M, Brownbridge LC, Harwood JL, Nicolaou A. 2017. Lipid functions in skin: Differential effects of n-3 polyunsaturated fatty acids on cutaneous ceramides, in a human skin organ culture model. Biochim Biophys Acta 1859: 1679-1689.

Kim J, Yun H, Cho Y. 2011. Analysis of ceramide metabolites in differentiating epidermal keratinocytes treated with calcium or vitamin C. Nutr Res Pract 5: 396-403.

Kim H, Kim J, Park J, Kim SH, Uchida Y, Holleran WM, et al. 2012. Water extract of Gromwell (Lithospermum erythrorhizon) enhances migration of human keratinocytes and dermal fibroblasts with increased lipid synthesis in an in vitro wound scratch model. Skin Pharmacol Physiol 25: 57-64.

Kober MM, Bowe WP. 2015. The effect of probiotics on immune regulation, acne, and photoaging. Int $J$ Women Dermatol 1: 85-89.

Kogot-Levin A, Saada A. 2014. Ceramide and the mitochondrial respiratory chain. Biochimie 100: 88-94.

Kolesnick RN, Goni EM, Alonso A. 2000. Compartmentalization of ceramide signaling: physical foundations and biological effects. $J$ Cell Physiol 184: 285-300.

Krutmann J, Gilchrest BA. 2006. Photoaging of skin. In: Gilchrest BA, Krutmann J, eds. Skin aging. New York: Springer Heidelberg, pp. 33-43.

Krutmann J, Bouloc A, Sore G, Bernard AB, Passeron T. 2017. The skin aging exposome. J Dermatol Sci 85: 152-161.

Merrill AH, Sandhoff K. 2002. Chapter 14 Sphingolipids: metabolism and cell signaling. In: Biochemistry of lipids and membranes, 4 th ed. Elsevier Science BV, pp. 373-407.

Merrill AH, Nixon DW, Williams RD. 1985. Activities of serine palmitoyltransferase (3-ketosphinganine synthase) in microsomes from different rat tissues. J Lipid Res 26: 617-622.

Mojumdar EH, Kariman Z, Van Kerckhove L, Gooris GS, Bouwstra JA. 2014. The role of ceramide chain length distribution on the barrier properties of the skin lipid membranes. Biochim. Biophys Acta 1838: 2473-2483.

Mouton RE, Venable ME. 2000. Ceramide induces expression of the senescence histochemical marker, beta-galactosidase, in human fibroblasts. Mech Ageing Dev 113: 169-181.

Oba C, Morifuji M, Ichikawa S, Ito K, Kawahata K, Yamaji T. 2015. Dietary milk sphingomyelin prevents disruption of skin barrier function in hairless mice after UV-B irradiation. PLoS One 10: e0136377.

Ohta H, Yatomi Y, Sweeney EA, Hakomori S, Igarashi Y. 1994. A possible role of sphingosine in induction of apoptosis by tumor necrosis factor--alpha in human neutrophils. FEBS Letters 355: 267-270.

Park K, Lee S, Lee YM. 2013. Sphingolipids and antimicrobial peptides: function and roles in atopic dermatitis. Biomol Ther 21: 251-257.

Park K, Kim YI, Shin KO, Seo HS, Kim JY, Mann T, et al. 2014. The dietary ingredient, genistein, stimulates cathelicidin antimicrobial peptide expression through a novel S1P-dependent mechanism. $J$ Nutr Biochem 25: 734-740. 
Pavicic T, Wollenweber U, Farwick M, Korting HC. 2007. Antimicrobial and anti-inflammatory activity and efficacy of phytosphingosine: an in vitro and in vivo study addressing acne vulgaris. Int J Cosmet Sci 29: 181-190.

Ponec M. 1991. Lipid metabolism in cultured keratinocytes. $A d v$ Lipid Res 24: 83-118.

Popa I, Portoukalian J. 2015. Distribution of gangliosides in human epidermis, dermis and whole skin. J Clin Exp Dermatol Res 6: 282-286.

Popa I, Bennaceur K, Abdul-Malak N, Perrier E, Schmitt D, Portoukalian J. 2006. Studies of compounds that enhance sphingolipid metabolism in human keratinocytes. Int $J$ Cosmet Sci 28: 53-59.

Popa I, Abdul-Malak N, Portoukalian J. 2010. The weak rate of sphingolipid biosynthesis shown by basal keratinocytes isolated from aged $v s$. young donors is fully rejuvenated after treatment with peptides of a potato hydrolysate. Int J Cosmet Sci 32: 225-232.

Popa I, Pin D, Remoué N, Osta B, Callejon S, Videmont E, et al. 2011. Analysis of epidermal lipids in normal and atopic dogs, before and after administration of an oral omega-6/omega-3 fatty acid feed supplement. A pilot study. Vet Res Commun 35: 501-509.

Popa I, Pin D, Remoué N, Osta B, Callejon S, Videmont E, et al. 2012. The lipid alterations in the stratum corneum of dogs with atopic dermatitis are alleviated by topical application of a sphingolipidcontaining emulsion. Clin Exp Dermatol 37: 665-671.

Popa I, Watson AL, Solgadi A, Butowski C, Allaway D, Portoukalian J. 2018. Linoleate-enriched diet increases both linoleic acid esterified to omega hydroxy very long chain fatty acids and free ceramides of canine stratum corneum without effect on proteinbound ceramides and skin barrier function. Arch Dermatol Res 403: $1845-1855$.

Spiegel S, Merrill AH Jr. 1996. Sphingolipid metabolism and cell growth regulation. FASEB J 10: 1388-1397.

Spiegel S, Milstein S. 2000. Functions of a new family of sphingosine-1-phosphate receptors. Biochim Biophys Acta 1484: $107-116$.

Tavakoli Tabazavareh S, Seitz A, Jernigan P, Sehl C, Keitsch S, Lang $\mathrm{S}$, et al. 2016. Lack of sphingosine causes susceptibility to pulmonary Staphylococcus aureus infections in cystic fibrosis. Cell Physiol Biochem 38: 2094-2102.

Thudichum JLW. 1884. A treatise on the chemical constitution of brain. London: Bailliere, Tindall and Cox. Available from https:// archive.org/stream/b23984570\#page/n0/mode/2up.

Tidhar R, Futerman AH. 2013. The complexity of sphingolipid biosynthesis in the endoplasmic reticulum. Biochim Biophys Acta 1833: 2511-2518.

Wilkes GL, Brown IA, Wildnauer RH. 1973. The biomechanical properties of skin. CRC Crit. Rev Bioeng 1: 453-495.

Yadav H, Jain S, Sinha PR. 2008. The effect of probiotic dahi containing Lactobacillus acidophilus and Lactobacillus casei on gastropathic consequences in diabetic rats. J Med Food 11: 62-68.

Young SA, Mina JG, Denny PW, Smith TK. 2012. Sphingolipid and ceramide homeostasis: Potential therapeutic targets. Biochem Res Intern. Article ID 248135, 1-12.

Cite this article as: Popa I. 2018. The concept of sphingolipid rheostat in skin: a driving force for new active ingredients in cosmetic applications. OCL 25(5): D507. 